\title{
Quantifying effect of concurrent draw on extraction zones in block caving mines using large scale 3D physical model
}

\author{
A. Halim*1, R. Trueman ${ }^{2}$ and R. Castro ${ }^{3}$
}

There remains a debate within the literature and among practitioners of caving methods as to the effect on draw zone geometry for the concurrent drawing of multiple drawpoints. Concurrent draw refers to an extraction schedule where a limited amount of material is drawn from each drawpoint before moving to the next drawpoint to draw the same amount. One hypothesis concludes that the flow geometries of a single drawpoint increase while another assumes no change from that of isolated draw. The largest 3D physical model constructed using gravel as the model media has been used to further investigate interactive draw of extraction zones as part of an International Caving Study (ICS) and Mass Mining Technology Project supported by major international companies with interest in caving methods. All extraction zones were measured in 3D. To date a maximum of 10 drawpoints have been modelled. Model results so far indicate no growth in the horizontal width of extraction zones using concurrent draw. Experiments conducted with multiple drawpoints that were spaced less than the width of isolated extraction zones showed that the combined horizontal area of draw appears to reduce with the increasing overlap of isolated extraction zones. The horizontal widths of extraction zones continued to increase within the height of the draw tested.

Keywords: Gravity flow, Granular materials, Multiple drawpoints interaction, Block caving, Physical modelling

\section{Introduction}

In large scale underground metalliferous mining methods, and in particular for caving mining methods, the characteristics of gravity flow of broken ore and waste rock in addition to draw management practices control the amount of valuable material recovered, the extent to which it is diluted by waste rock. Gravity flow characteristics also influence decisions on extraction level layout, in particular the spacing and location of drawpoints. All these have a large impact on the economics of mining. ${ }^{1}$

Many factors are known to influence flow behaviour in caving environments. These include initial design factors, operational factors, and the natural gravity flow properties of broken rock. ${ }^{2}$ Knowledge of the natural flow properties of rock and how these are influenced by design and operational factors is a prerequisite for optimal extraction and/or production level design.

There is currently debate within the literature of caving methods as to whether or not the consecutive

\footnotetext{
${ }^{1}$ Barrick Australia Pacific, Kanowna Belle Mine \& Western Australian School of Mines, Curtin University of Technology, Kalgoorlie, Australia (formerly University of Queensland, Brisbane, Australia)

${ }^{2}$ Strata Engineering (Australia), Newcastle, Australia (formerly University of Queensland, Brisbane, Australia)

${ }^{3}$ University of Chile, Santiago, Chile (formerly University of Queensland, Brisbane, Australia)

*Corresponding author, email halimadrian@gmail.com
}

draw from adjacent drawpoints influences the behaviour of broken rock under flow. Researches conducted in physical models have shown that the zones that define the extraction zone and movement zone increases due to the drawing of multiple adjacent drawpoints..$^{3-6,8}$

This paper describes the results of an experimental programme using the largest 3D physical model ever constructed to study the gravity flow of broken rock in a mining environment. An experimental study of the interaction of extraction zones for a range of drawpoint spacings is described and preliminary conclusions made relative to the effect of concurrent draw on ore recovery and dilution.

\section{Previous work}

In understanding and quantifying the flow of broken rock, there are two main concepts describing the shapes formed by material moving and extracted in granular flow. ${ }^{7}$ The first of these is the limiting outline that defines the original location of material that has been drawn from a drawpoint at any given point in terms of mass, i.e. the extracted material. The second concept is the limiting outline that defines the boundary between stationary material and material that has moved from its original location at a given extracted mass, i.e. the material under flow.

Various authors have referred to these shapes in different ways in the literature. The shape that defines 


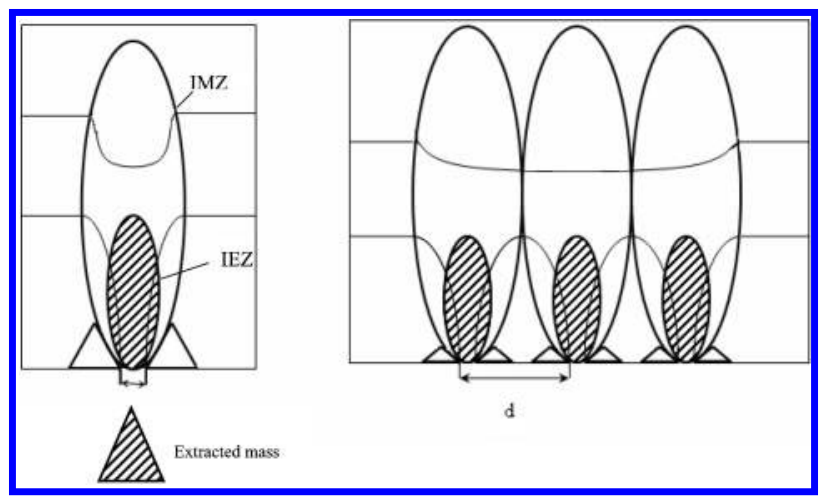

1 Movement and extraction zones when point of draw is worked in isolation (left): mass flow as consequence of interaction of movement zones when drawpoints are spaced at distance $d$

the original location of the extracted material has been defined in various places as the ellipsoid of motion, draw ellipse, the draw body, the draw envelope, the ellipsoid of draw or the isolated draw zone. The authors will use the term isolated extraction zone (IEZ) in this paper. The shape that defines the limits of material that has moved has been called, among other things, the limit ellipsoid, the loosening ellipsoid, the ellipsoid of movement, the movement envelope or the draw zone. The authors use the term isolated movement zone (IMZ) in this paper. Figure 1 illustrates these concepts for drawing material from a single drawpoint in isolation from other flow zones.

In block caving mines ore is drawn from multiple drawpoints in accordance with some predefined draw sequence depending on the local draw control strategy. Current design guidelines in caving mines are based on the interaction of isolated movement zones in ideal draw conditions. $^{5,8}$ The production level layout and the distance between drawpoints ( $d$ in Figure 1) should allow the ore waste interface to move in mass in order to avoid early dilution. As a result of mass flow most of the ore will be extracted with minimal dilution as ore/waste boundary will be lowered uniformly.

It has been possible, albeit in a limited number of cases, to measure IEZs at the mine scale in sublevel caves. ${ }^{9-11}$ However, because of the greater complexity of block caving, the determination of IEZs in practice has not been possible to date. Current understanding of extraction zones in isolation has been largely based on studies on physical models..$^{3,4,10,12,14}$ Studies of the geometry of extraction zones under multiple drawpoints have indicated that under the draw of multiple drawpoints the flow characteristic of gravel changes. Peters $^{3}$ observed extraction zones in a 2D gravel model and concluded that when drawpoints were spaced at a nominal distance of $1 \cdot 14$ times of the average IEZ at full height the overlap of extraction zones occurred. An expansion of extraction zones due to the drawing of multiple drawpoints (in this case 2) was thus concluded. However, only a very limited number of experiments were carried out by Peters and no dispersion in IEZs was measured. The observed expansion of IEZs concluded by Peters could therefore be a result of dispersion rather than a change in extraction zone geometry due to the drawing of multiple drawpoints.

Marano $^{4}$ observed in $3 \mathrm{D}$ sand models that the combined movement zones of a number of drawpoints

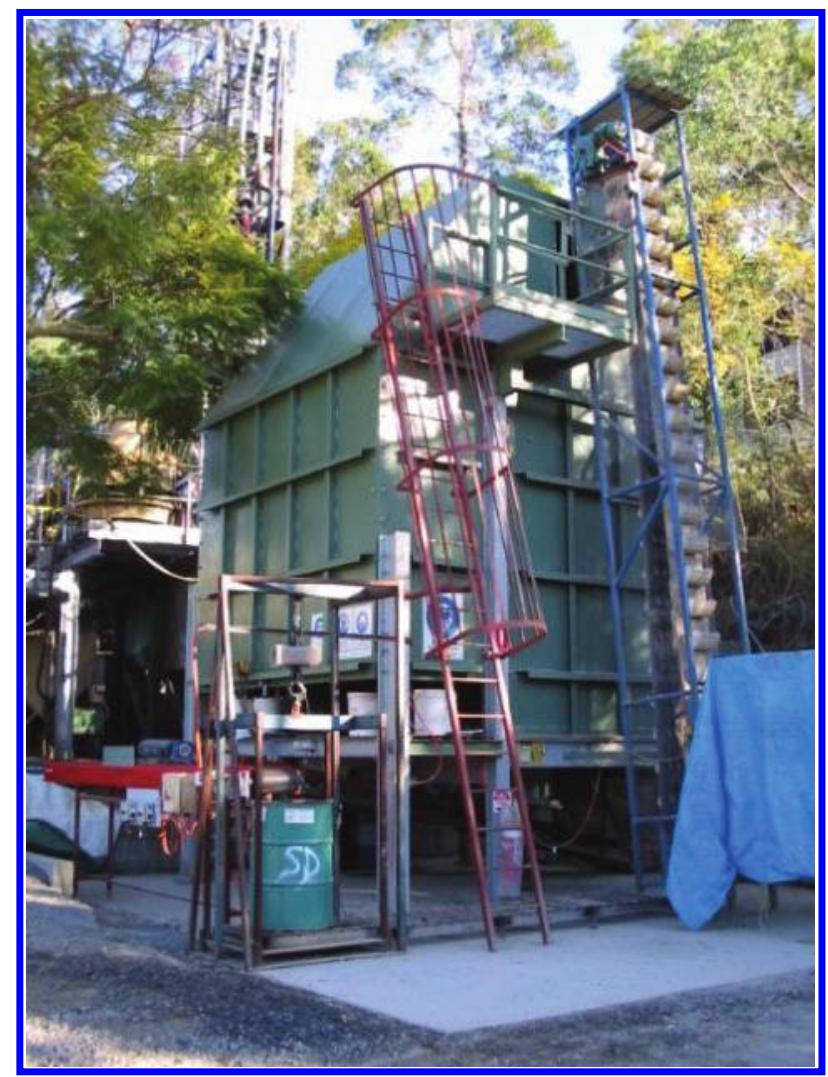

2 Physical model (ladder shown is $6.5 \mathrm{~m}$ long)

were larger than in isolated draw. Interaction of IMZs was found when drawpoints were spaced up to $1.5 \times$ IMZ. Laubscher has proposed design criteria based on Marano's conclusions of critical interaction limits for movement zones. ${ }^{5,8}$ In view of that the authors investigated the geometry and interaction of movement zones, which found contrasting results than Marano's. ${ }^{12}$ Based on this finding, it is necessary to investigate the geometry and interaction of extraction zones as these zones define material that is drawn from the drawpoints, which is the topic of this paper.

\section{Three-dimensional physical model}

The physical model was designed to run simulations of flow for block caving mines under both isolated draw and interactive draw conditions. Variation of design parameters such as drawpoint spacing and block height were also allowed for under this design. Under the block caving interactive draw zone configuration the physical model had the internal dimensions of $3.5 \times 2.5 \times 3.3 \mathrm{~m}$ (width $\times$ depth $\times$ height), and held approximately 55 tonnes of aggregate (see Fig. 2). This represents the largest $3 \mathrm{D}$ physical model ever constructed to study flow using gravel as the model media.

The physical model was set to geometrical scales of $1: 30$, and then reduced into $1: 100$ with respect to current design practice. Model height was $3300 \mathrm{~mm}$, which represented a block of $100 \mathrm{~m}$ high scaled (in $1: 30$ scale) and $330 \mathrm{~m}$ high scaled (in 1:100 scale).

In the $1: 30$ scale model, drawpoints were $120 \times 100 \mathrm{~mm}$ (width $\times$ high) $(3.6 \times 3.0 \mathrm{~m}$ at that scaled dimensions) and open into a drawbell with vertical brow and minor apex angle of $68.6^{\circ}$. These dimensions are based on a drawpoint and drawbell design used at the 
CODELCO's El Teniente 4 South mine in Chile. ${ }^{13}$ The height of the drawbell above the floor of the drawpoint was $500 \mathrm{~mm}$ (15 m scaled) while its width was $433 \mathrm{~mm}$ (13 m scaled).

In the 1:100 scale models, drawpoints were $36 \times$ $30 \mathrm{~mm}$ (wide $\times$ high) $(3.6 \times 3.0 \mathrm{~m}$ at that scaled dimensions). The decision to reduce the scale to $1: 100$ was to enable models to simulate a more realistic block height, as the 1:30 model was only able to simulate a maximum block height of $100 \mathrm{~m}$ which is far below the height in current mines (130-500 m). This model was also able to investigate the geometry of an IEZ that is surrounded by other IEZs under interactive draw, which was not possible at a scale of $1: 30$. This made the model closer to a real mine condition, and simulation of the Esmeralda block in El Teniente Mine in Chile was carried out, which will be explained in detail in the sections on 'Isolated draw' and 'Concurrent draw from 10 drawpoints'. The authors carried out investigation on this change of scales and found no observed distortion between them. ${ }^{14}$

No drawbell was used in this model due to practical reason. Power ${ }^{10}$ demonstrated that the drawbell does not have effect upon the geometry of IEZ.

The methodology used to carry out experiments is described in a previous publication. ${ }^{14}$

\section{Model assumptions}

The following assumptions and simplifications were made to study the interaction limit of IEZs in block caving through physical modelling:

(i) it is assumed that the rock mass has caved; in this context, the rock mass could be considered a granular mass composed of non-cohesive and coarse fragments that flow slowly towards the drawpoints under the action of gravity

(ii) the granular mass is characterised through its size, shape and angle of friction and could be considered heterogeneous (composed of large and fine particles) and isotropic

(iii) the granular flow occurs in a $3 \mathrm{D}$ environment

(iv) as particles flow to drawpoints, some rock breakage occurs through abrasion but it is negligible

(v) the geometries of the flow zones at different geometrical scales in the large physical model are comparable as long as the materials have an equal friction angle and particle shape.

\section{Materials and instrumentation}

The material used in the experiments was crushed phyllite from a local quarry. The gravel was air dried before being used in the experiments. This had the objective of avoiding cohesion due to capillary effects on the material's fine fraction as it was found that results of the physical model might be able to be scaled up to in situ scale as long as the material is non-cohesive. ${ }^{15}$

At a geometric scale of $1: 30$, a wide distribution of gravel size was used, which intended to match an in situ distribution. The particle size distribution is shown in Fig. 3. If scaled up, the gravel represents broken rock of a mean size of $0.54 \mathrm{~m}$, with a maximum size of $1.2 \mathrm{~m}$, which represents a relatively coarse cave fragmentation.

The aspect ratios appear to be similar for all gravel sizes, the characteristic shape being long relative to the width and wide relative to the depth (length/width 1.6

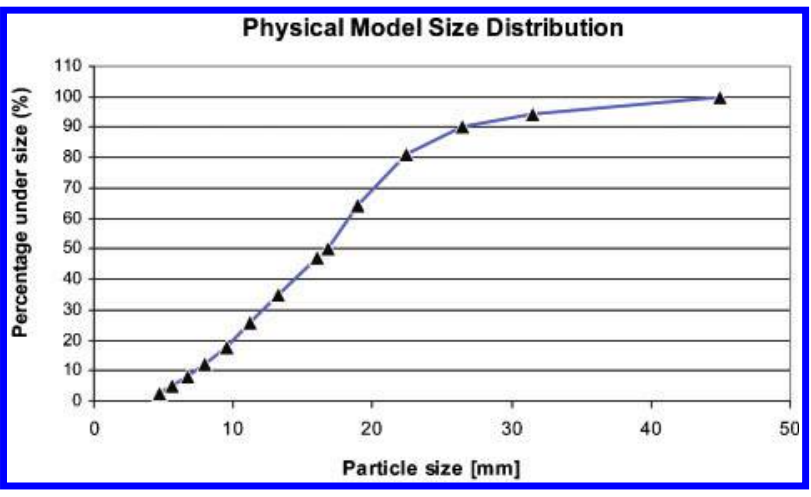

3 Particle size distribution of 1:30 model media

$\mathrm{SD}=0 \cdot 4$, length/height $2 \cdot 8 \mathrm{SD}=1 \cdot 4$, width/height $1 \cdot 7$ $\mathrm{SD}=0 \cdot 9$ ). Tests to determine the shear properties of the gravel were undertaken in a large diameter shear box. The normal loads used in the tests ranged between 15 and $65 \mathrm{kPa}$ to match those within the physical model. A mean friction angle of $45^{\circ}$ was noted.

At a scale of $1: 100$, the media did not have a wide distribution as in the $1: 30$ model and the mean particle size was smaller, $7 \mathrm{~mm}$. The reason for this was due to the size of the drawpoint in this model; fragments larger than $20 \mathrm{~mm}$ could not be used since it would create hang-ups. However, it was demonstrated that the width of draw was controlled by the mean particle size, not the distribution. ${ }^{10}$ When scaled, it represents $0.7 \mathrm{~m}$ fragment size, which is a typical mean size of caved ore in modern block caving mines. The aspect ratio was similar with the media in the $1: 30$ model. The friction angle of the model media was similar to the $1: 30$ scale at $44^{\circ}$.

Measurement of extraction zones was undertaken through back analysis of recovered labelled markers, as described in a previous publication. ${ }^{14}$

\section{Model experiments and results}

A number of experiments were carried out to test the effect of drawing multiple drawpoints concurrently. These were:

(i) isolated draw from a single drawpoint to measure the IEZ in both $1: 30$ and $1: 100$ scale models

(ii) study of interaction of extraction envelopes:

(a) two drawpoints located at various spacings in a single drawbell. The length was set at $1100 \mathrm{~mm}$, which corresponds to a separation distance between drawpoints of $15 \%$ with respect to the IEZ measured in the first test. This was done in the $1: 30$ scale model

(b) ten drawpoints. The simulation was carried out according to conditions at the Esmeralda block in El Teniente Mine in Chile. The separation between drawpoints was $1 \cdot 15$ times the width of the IEZ measured in the first test. This was done in the $1: 100$ scale model

(iii) study of overlap of IEZs, which was done in the $1: 30$ scale model.

(a) Two adjacent drawpoints located in a single drawbell. The length was set at 500 and $700 \mathrm{~mm}$ respectively; the former 


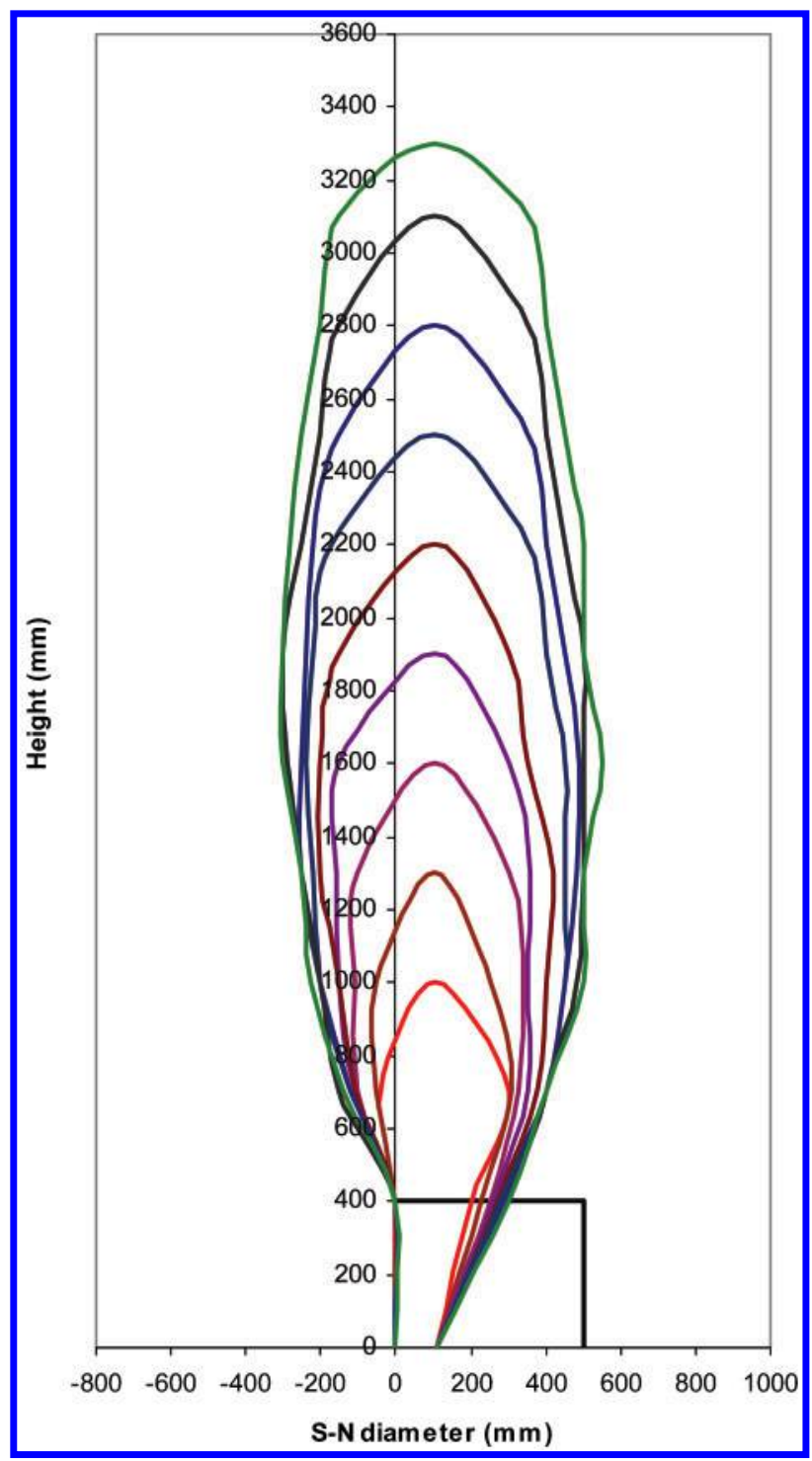

4 Widths of extraction zone as function of height of draw

referred at a $1: 30$ scale from that used at El Teniente 4 South Mine in Chile

(b) study of overlap of IEZs from two adjacent drawbells. Geometry of these drawbells referred to that used at El Teniente 4 South Mine in Chile.

\section{Isolated draw}

In the $1: 30$ scale model, the maximum width of the IEZ was $800 \mathrm{~mm}$ for the full $3300 \mathrm{~mm}$ height of draw. If scaled at the geometrical scale used in the model those values would represent an IEZ width of $23.4 \mathrm{~m}$ at $100 \mathrm{~m}$ height. Figure 4 shows that the width of the extraction zone increases with the height of draw. The centroid of the extraction zone moves with the mass draw in the vertical plane across the drawbell. Initially the centroid was located at the drawpoint brow and moved to a final position located approximately $100 \mathrm{~mm}$ inside the drawbell. The final position of the centroid was reached when the IEZ was $1100 \mathrm{~mm}$ in height. In the section across the drawpoint the centroid is approximately at the centre of the drawpoint. Repeats of the same test were carried out and a standard error of $36 \mathrm{~mm}$ for the width of the IEZ was calculated.

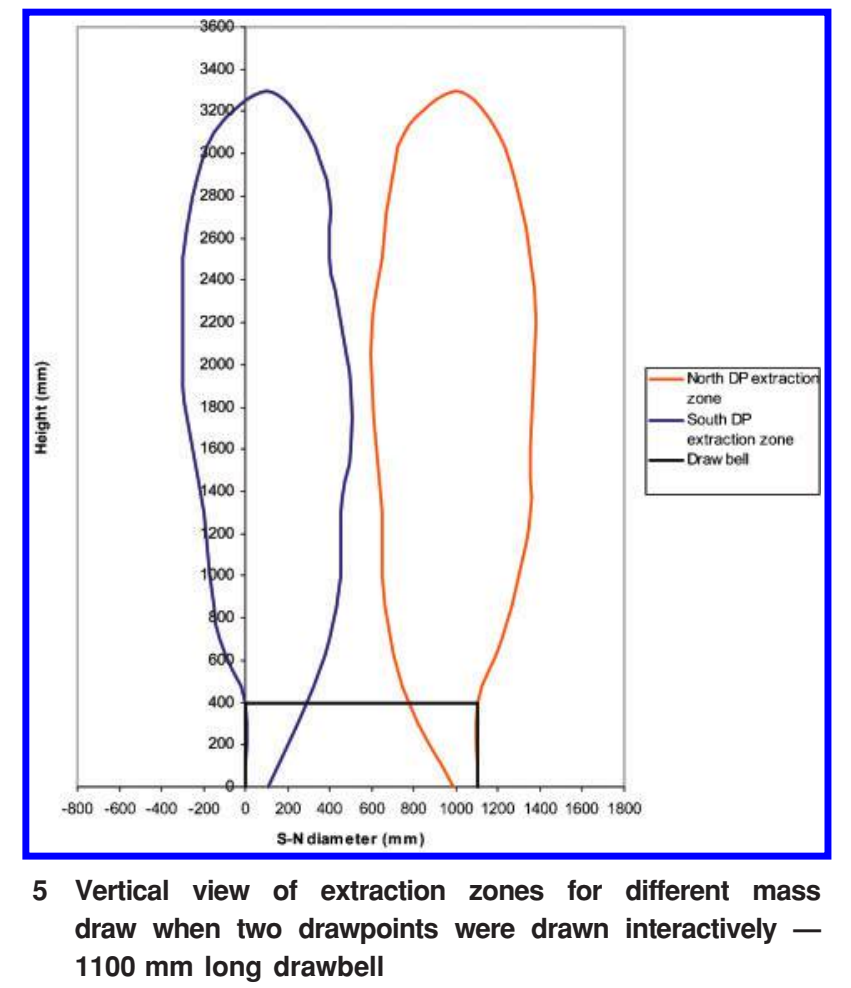

In the 1:100 scale model, the draw was carried out until the IEZ reached $1400 \mathrm{~mm}$ (140 m scaled) high. This was achieved because with this model, the authors were able to simulate drawing in a real mine, in this case the Esmeralda block in El Teniente Mine, which has a block height of $140 \mathrm{~m}$. However, the model was filled up to its maximum height, $3300 \mathrm{~mm}$ (330 m scaled). This was done to simulate the effect of overburden upon the geometry of extraction zones under concurrent draw, which matched the condition at the Esmeralda block in El Teniente Mine. There was an opinion within industry that the overburden might have an effect upon the geometry of extraction zones under concurrent draw, so this test and subsequent 10 drawpoints gave one an opportunity to test this opinion. There were three tests carried out in order to obtain the dispersion of the width of the IEZ. These tests produced the same maximum width, which was $420 \mathrm{~mm}$.

\section{Concurrent draw from two drawpoints in long drawbell}

In order to test the limit of interaction between extraction zones, the drawbell was extended to a length of $1100 \mathrm{~mm}$. This corresponds to an effective separation between centroids of extraction zones of $1 \cdot 15$ times the average maximum width of the IEZ at $3300 \mathrm{~mm}$ full height of draw respectively. Figure 5 shows the results of this experiment. The results are shown as a section looking across the drawbell. At the full height of draw the widths of the individual IEZs were found to be $785 \mathrm{~mm}$ on average. These are slightly less than achieved for isolated draw but within the range of the dispersion of results for a repeat of the same test that was carried out in previous work in the same model. ${ }^{10}$ It is clear therefore that at this drawpoint spacing there was no change in the shape of the extraction zones due to concurrent draw. The extraction zones of the two 


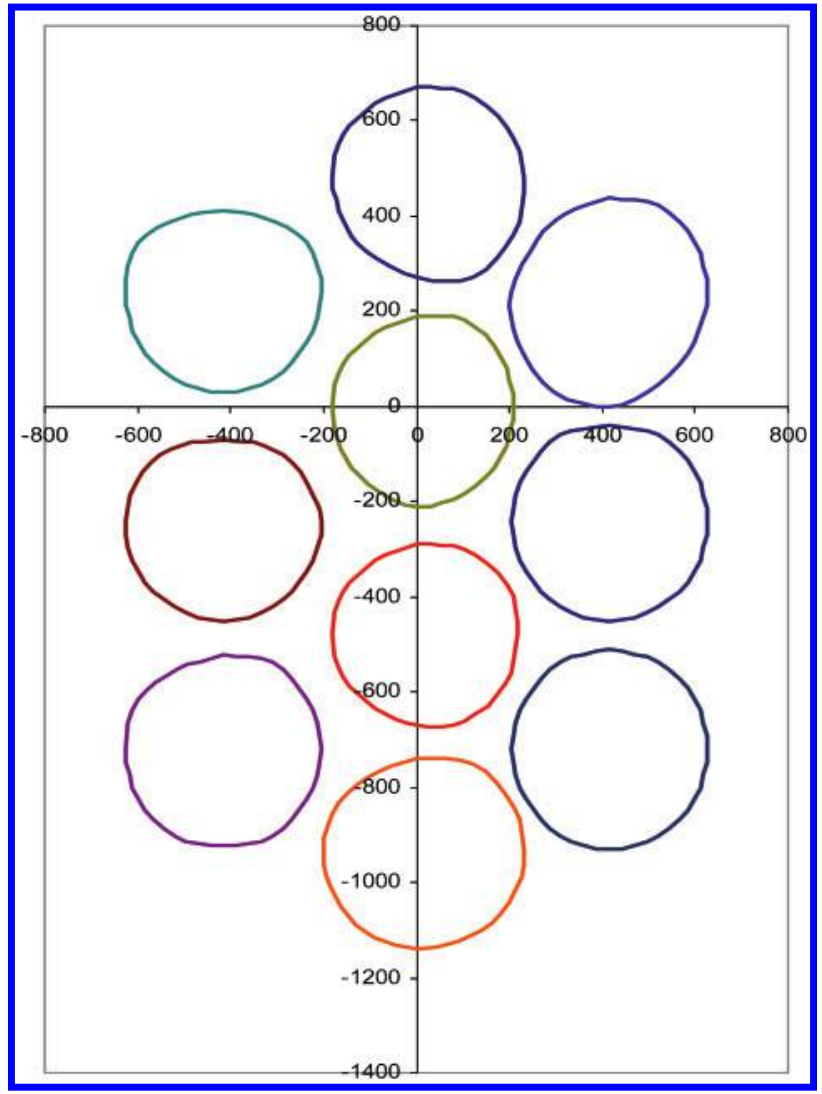

6 Mid section of extraction zones in 10 drawpoints test

drawpoints therefore acted in a similar manner to the isolated extraction draw.

\section{Concurrent draw from 10 drawpoints}

As has been mentioned in the section on 'Isolated draw', this test was aimed to simulate draw for the Esmeralda block in El Teniente Mine. The separation between centroids of extraction zones was $480 \mathrm{~mm}$, which corresponds to $1 \cdot 15$ times the maximum width of IEZ that was found in the isolated draw experiment at a draw height of $1400 \mathrm{~mm}$. Figure 6 shows the plan view of the mid section of the extraction zones. It is obvious that there is no change in the shape of the extraction zones due to concurrent draw. As the model was filled up to $3300 \mathrm{~mm}$, which means that the draw was carried out under overburden load upon the extraction zones, the indication is that the overburden does not have any effect upon the geometry of extraction zones under concurrent draw.

\section{Concurrent draw from two drawpoints in short drawbell - geometry of combined extraction zones}

As part of the experimental program the effect on the geometry of combined extraction zones was investigated when the spacing between drawpoints was less than the average width of the IEZ at the full height of draw. It was expected that the extraction zones of individual drawpoints would overlap. The effect of overlapping of extraction zones was investigated using two different drawbell lengths. As with the previous tests material was drawn concurrently. The first test was at $500 \mathrm{~mm}$ and the second at $700 \mathrm{~mm}$ drawbell length using the same material as before. In view of the offset of the IEZ

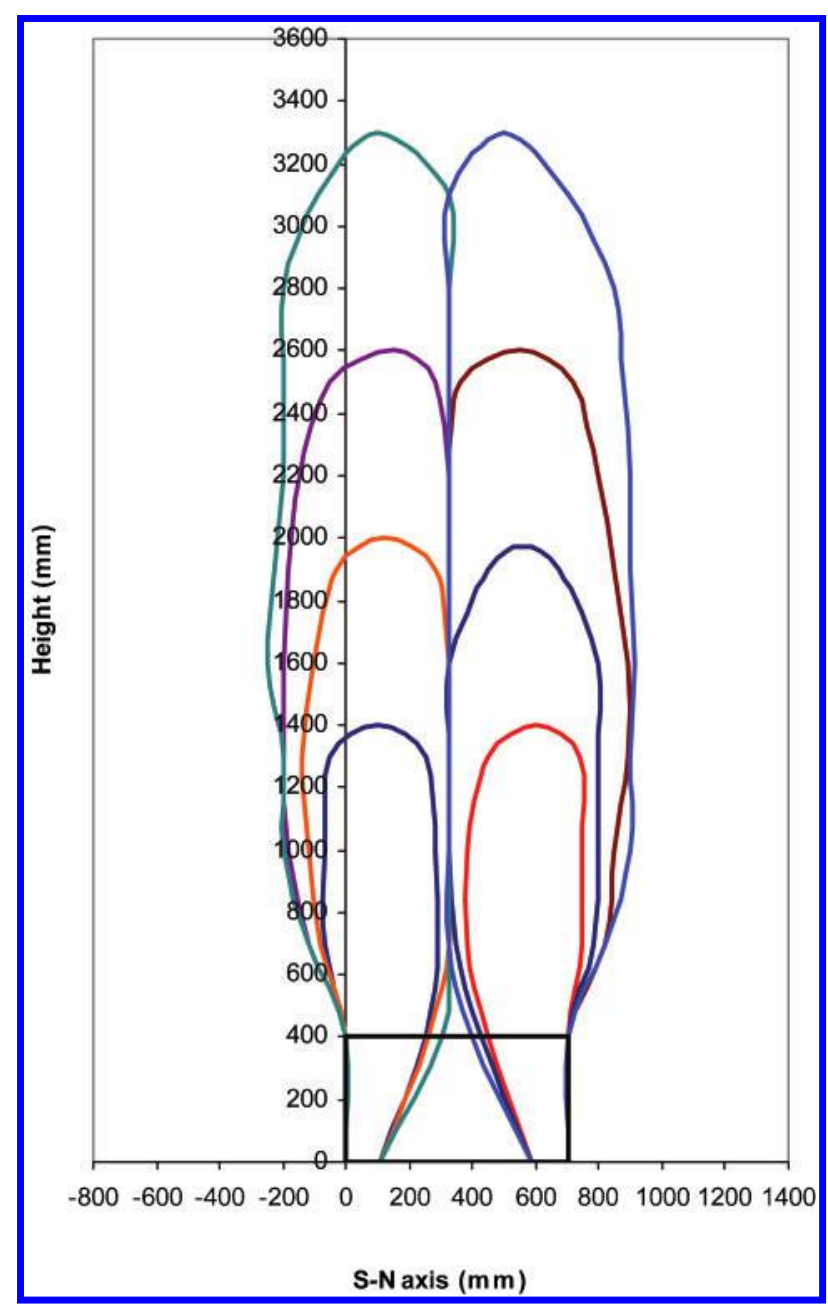

7 Extraction zones for each drawpoint, looking across drawbell $-700 \mathrm{~mm}$ long drawbell

centroid the extraction zones were at an effective distance of 300 and $500 \mathrm{~mm}$ respectively.

Figure 7 shows the development of the extraction zones as the material was drawn for the $700 \mathrm{~mm}$ drawbell. It can be seen that at up to a certain height of draw the extraction zones of both drawpoints were in isolation. Afterwards the individual extraction zones merged as they reached the IEZ width at which they would overlap. It is interesting to note that material immediately above each drawpoint was extracted by the closest exit point, meaning that lateral mixing did not occur when the drawpoints were drawn concurrently. The extraction zones for each drawpoint were separated by a well defined boundary, characterised by a vertical plane between drawpoints. The same pattern was confirmed by observations in the $500 \mathrm{~mm}$ drawbell experiment.

The height of the extraction zones reached the full height of the model faster in terms of mass than that in isolation. For the $500 \mathrm{~mm}$ drawbell an average of $1420 \mathrm{~kg} /$ drawpoint was drawn while for the $700 \mathrm{~mm}$ drawbell $1700 \mathrm{~kg} /$ drawpoint when the extraction zones reached $3300 \mathrm{~mm}$ in height. This is less when compared to the almost $2000 \mathrm{~kg}$ drawn to reach the same height for an isolated point of draw.

The geometry of the combined extraction zones was slightly different from that of the simply superimposing IEZ. Figure 8 shows a section passing through the 


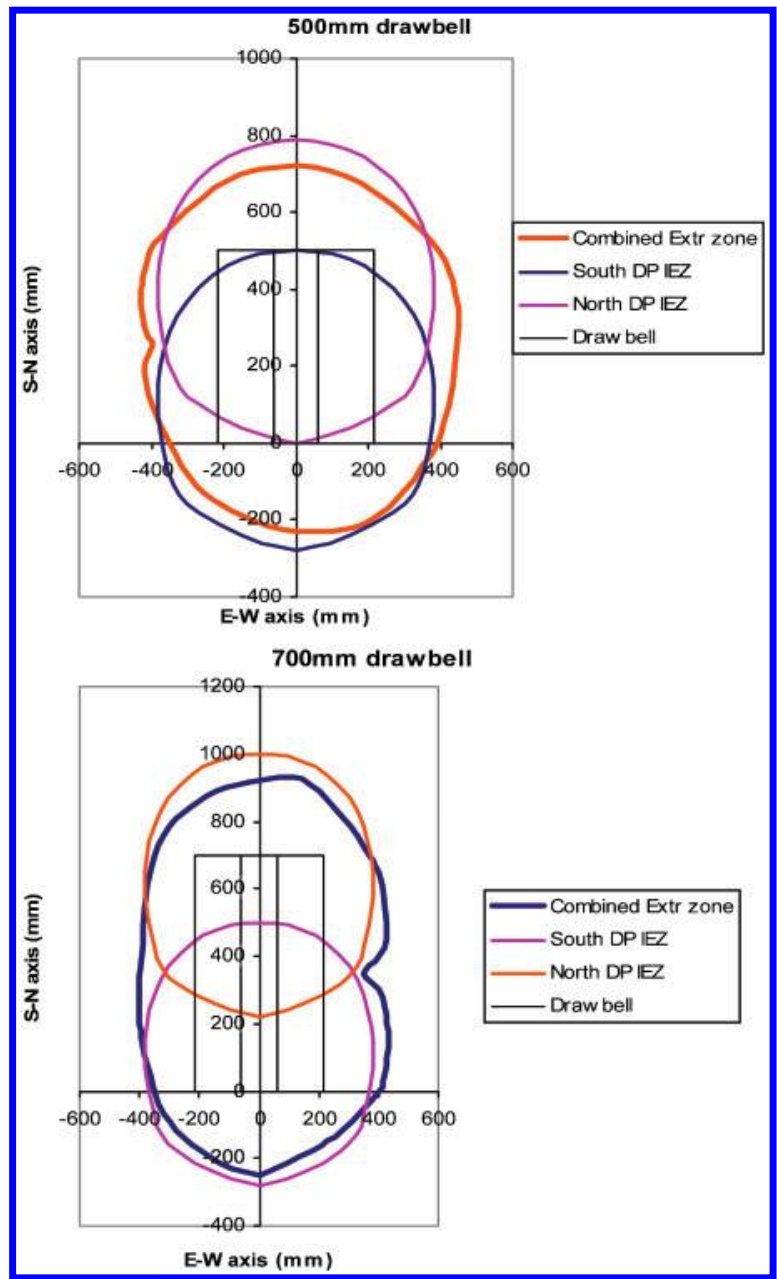

8 Plan view at mid height of draw with isolated extraction zones superimposed at the same height of draw -500 and $700 \mathrm{~mm}$ drawbell lengths

$1650 \mathrm{~mm}$ level in which the authors have plotted the extraction zones obtained in these experiments and the superimposed average IEZ geometry calculated from the isolated draw tests at the full height of draw. The combined extraction zones for the $500 \mathrm{~mm}$ drawbell tend to be slightly narrower in the direction along the drawbell (N-S in Fig. 8) and wider in the direction across the drawbell (E-W in Fig. 8). For the $700 \mathrm{~mm}$ drawbell experiment, the combined zones showed similar qualitative differences in the width but to a less extent.

The difference between the length of the extraction zone in the $\mathrm{N}-\mathrm{S}$ direction and that derived from superimposing IEZs was less for the $700 \mathrm{~mm}$ drawbell when compared to the $500 \mathrm{~mm}$ drawbell. These results suggest that as the degree of overlap between adjacent extraction zones is increased, the shape of the combined extraction zone differs from that of superimposed IEZs.

\section{Concurrent draw from four drawpoints with short minor apex}

In this experiment, concurrent draw was carried out in four drawpoints located in two adjacent drawbells. The layout is a scaled down version of the one used in El Teniente 4 South Mine in Chile. ${ }^{13}$ In the physical model the scaled IEZ was found to be wider than the spacing between drawpoints. Therefore, it was expected that

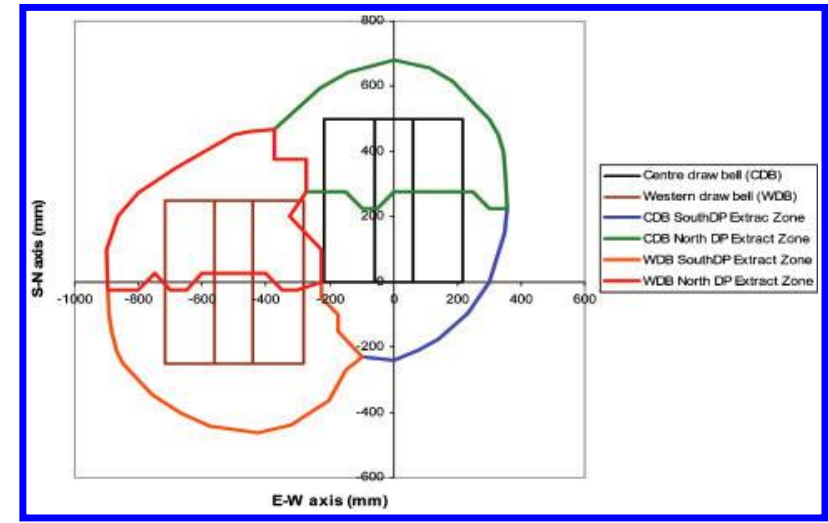

9 Plan view at mid height of draw with each drawpoint extraction zone - four drawpoints in two $500 \mathrm{~mm}$ drawbells, $570 \mathrm{~mm}$ separation

overlap of IEZs would occur and all material between drawbells would be extracted.

In agreement with the results from the one drawbell experiment, material that was located immediately above the drawpoint was extracted by the nearest exit (see Fig. 9). In this experiment a total of $1100 \mathrm{~kg}$ was drawn from each individual drawpoint before the extraction zone reached the surface. This suggests that the amount of material drawn from a drawpoint will decrease as its extraction zone is overlapped by an increasing number of adjacent extraction zones.

Figure 10 shows the plan view at mid height of the combined extraction zones for the full height of draw. The average overlapping individual IEZ for the four drawpoints is superimposed over the combined actual extraction zone. It can be seen in Fig. 10 that the limit of the combined extraction zones for the four drawpoints drawn concurrently is smaller than the limit defined by simply superimposing the isolated extraction zone limits for each drawpoint. The effect of overlapping extraction zones is that the shape of the combined extraction zones is narrower than the shape defined by superimposing isolated extraction zones for each drawpoint.

In practice it is of interest to know the area of influence of the drawpoints in terms of extracted area. Table 1 shows a comparison between the actual extracted area and that calculated from superimposing IEZs. The calculations for the superimposed IEZ were based on the average IEZ width of $755 \mathrm{~mm}$ at half of its

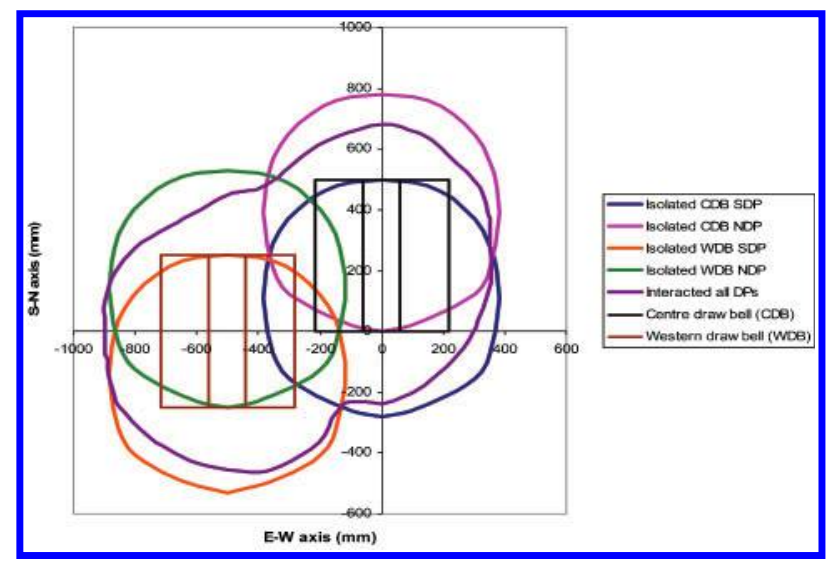

10 Concurrent draw from four drawpoints in two $500 \mathrm{~mm}$ drawbells, $570 \mathrm{~mm}$ separation - plan view at mid height of draw with isolated drawzones superimposed 
Extracted area, $\mathrm{mm}^{2}$

\begin{tabular}{llcll}
\cline { 3 - 4 } Experiment & Height IEZ, $\mathrm{mm}$ & $\begin{array}{l}\text { Mass drawn/ } \\
\text { drawpoint, Kg }\end{array}$ & $\begin{array}{l}\text { Calculated from overlapping } \\
\text { average IEZs }\end{array}$ & $\begin{array}{l}\text { Combined extraction } \\
\text { zones }\end{array}$ \\
\hline $500 \mathrm{~mm}$ drawbell & 3300 & 1450 & 666952 & 694000 \\
$700 \mathrm{~mm}$ drawbell & 3300 & 1700 & 789600 & 756800 \\
$500 \mathrm{~mm} \times 4$ drawpoints & 1500 & 300 & 548000 & 548000 \\
& 2100 & 500 & 817600 & 714400 \\
& 2700 & 800 & 1042800 & 886400 \\
& 3300 & 1150 & 1173600 & 983600 \\
\hline
\end{tabular}

maximum height. The standard error for the area was calculated at $33 \cdot 371 \mathrm{~mm}^{2}$. From Table 1 , it is observed that the area of influence was not different within the range of dispersion observed for the area, between the superimposed and combined extraction zones for the 500 and $700 \mathrm{~mm}$ drawbell length experiments. However, in the four drawpoints experiment there was a decrease in the area of the extraction zone that is significant at the $95 \%$ confidence interval. This difference in area was significant after enough overlap of extraction zones had occurred, in terms of the height that had reached $2100 \mathrm{~mm}$ after the IEZ.

\section{Discussion and conclusions}

There is currently debate within the literature with respect to the effect upon the extraction zone geometry of drawing multiple adjacent drawpoints interactively. One theory suggests that the area of influence of drawpoints can increase significantly with interactive draw if drawpoints are appropriately spaced relative to the isolated extraction zone geometry. Another suggests that the areas of influence remain unchanged with respect to isolated draw.

The largest 3D physical model constructed to study gravity flow in caving mines was used to study the effect of concurrent draw in a block caving geometry. To date a maximum of 10 drawpoints have been modelled. The indications to date are that horizontal extraction zone dimensions do not increase with interactive draw. Even when drawing under overburden load, there is no expansion of extraction zones.

In a previous publication, ${ }^{14}$ in which the authors investigated the interaction of movement zones and found no expansion of them under concurrent draw, it was suggested that current interactive draw theory appears to be largely derived from sand models. The use of a very low friction angle boundary condition that inhibits stress arching in the sand models may be the reason that this occurred. The media that was used in physical models discussed in this paper has a friction angle close to in situ caved material. Also, the shape of particles (angular) is more similar to in situ caved material than to sand (round). Therefore, it can be reasonably said that this physical model is significantly closer to in situ conditions when compared to sand models.

The extraction area, when the extraction zones overlapped, was smaller than would be obtained from overlapping isolated extraction zones. The width of extraction zones continued to increase up to the full height of draw. The centroids of the extraction zones were located $100 \mathrm{~mm}$ inside the drawbell. Those factors could adversely contribute to the recovery of ore located over the major apex in the model.

In this paper, the actual values obtained in the model have been published without reference to scaled values. While there is evidence from full scale trials in sublevel caving mines that results from this large scale model could be scalable to the mine scale, ${ }^{10,14}$ it should be acknowledged that to date no full scale trials have been successfully completed in block caves.

\section{Acknowledgements}

The paper describes a component of work carried out within the International Caving Study (ICS II) and Mass Mining Technology Projectrun through the University of Queensland's Julius Kruttschnitt Mineral Research Centre, in Brisbane Australia. Sponsors include: BHPBilliton, CODELCO, DeBeers, LKAB, Newcrest Mining, Northparkes Mines, Rio Tinto, Xstrata Copper, Orica and Sandvik Tamrock. Their support and recommendations for the direction taken in the ICS II Gravity Flow research are appreciated. The authors are also grateful to Dr. Gideon Chitombo and Dr. Geoff Just from the University of Queensland for their contributions throughout the research.

\section{References}

1. E. T. Brown, Block caving geomechanics, 2003, Brisbane, Julius Kruttschnitt Mineral Research Centre, the University of Queensland.

2. R. Kvapil, 'Sublevel Caving,' in SME Mining Engineering Handbook, (ed. H. L. Hartman), 2nd edition, pp. 1789-1814, 1992, Littleton, Society of Mining, Metallurgy and Exploration.

3. D. C. Peters, 'Physical Modelling of the Draw Behaviour of Broken Rock in Caving,' Ouarterly of Colorado School of Mines, 1984, vol 79.

4. G. Marano, 'The interaction between adjacent draw points in free flowing materials and it application to mining,' Chamber of Mines Journal, 1980, vol. 22, pp. 25-32.

5. D. H. Laubscher, 'Cave mining-the state of the art,' The Journal of the South African Institute of Mining and Metallurgy, 1994, October, pp. 279-293.

6. T. G. Heslop and D. H. Laubscher, 'Draw Control in Caving Operations on Southern African Chrysotile Asbestos Mines,' in Design and Operation of Caving and Sublevel Stoping Mines, SME-AIME, NewYork, 1981, pp 755-774.

7. R. Kvapil, 'Gravity Flow of Granular Materials in Hoppers and Bins part 1,' International Journal of Rock Mechanics and Mining Sciences, 1965, vol. 2, pp. 35-41.

8. D. H. Laubscher, 'Block Caving Manual,' Julius Kruttschnitt Mineral Research Centre, the University of Queensland., Brisbane, 2000. Report prepared for International Caving Study (ICS) I.

9. I. Janelid, 'Study of the Gravity Flow Process in Sublevel Caving,' in Proceedings of the International Sublevel Caving Symposium Atlas Copco, Stockholm, 1972

10. G. R. Power, 'Modelling Granular Flow in Caving Mines: Large Scale Physical Models and Full Scale Experiments,' PhD thesis, the University of Queensland, Australia, 2004. 
11. B. Hollins and J. Tucker, 'Drawpoint analysis using a marker trial at the Perseverance Nickel Mine, Leinster, Western Australia', in Proceedings MassMin 2004, Instituto de Ingenieros de Chile, Santiago, 2004, pp 498-502.

12. R. Trueman, R. Castro and A. Halim, 'Study of multiple drawzone interaction in block caving mines by means of a large 3D physical model', International Journal of Rock Mechanics and Mining Sciences, in press, 2008.

13. D. E. Julin, 'Block Caving,' in SME Mining Engineering Handbook, (ed. H. L. Hartman), 2nd edition, pp. 1815-1836, 1992, Littleton, Society of Mining, Metallurgy and Exploration.

14. R. Trueman, R. Castro and A. Halim, 'A study of isolated draw zones in block caving mines by means of a large 3D physical model', International Journal of Rock Mechanics and Mining Sciences, 2007, vol 44, pp 860-870.

15. Halim, A. E., 'Study of the influence of interactive draw upon drawpoint spacing in block and sublevel caving mines', $\mathrm{PhD}$ thesis, the University of Queensland, 2006.

\section{Authors}

Dr Adrian Halim is Production Engineer at Barrick's Kanowna Belle mine and University Associate at Western Australian School of Mines, Curtin University of Technology, both are in Kalgoorlie, Western Australia. He gained ME (2001) and PhD (2006) at the University of Queensland. He has considerable experience in practical and research aspect of underground mining engineering (metalliferous and coal), having worked as mining engineer at Freeport Indonesia and Anglo Coal Australia, and as research scholar at the University of Queensland.

Dr Robert Trueman is Principal Geotechnical Engineer at Strata Engineering (Australia) in Newcastle, New South Wales. Having several years direct industrial experience with the Anglo American Corporation of South Africa and the National Coal Board of the UK, he has worked in teaching and research at Universities in Australia, South Africa and the UK and as a Research Group Manager with CSIRO Australia. He has managed a wide variety of R\&D mining projects. He has supervised several PhD students to completion.

Dr. Raul Castro gained his BSc (2001) and Mining Engineering degrees (2001) from the University of Chile, Santiago, Chile and a PhD in Mining Engineering at the University of Queensland. $\mathrm{He}$ is currently Assistant Professor at the Mining Engineering Department at the University of Chile. He has been involved in research topics relating to block cave mining over the last several years. He has also worked as a mining engineer in areas related to long term scheduling at CODELCO's El Teniente mine. 